\title{
AN IOT BASED ARCHITECTURE FOR SMART FARMING
}

\author{
D. S. Bhupal Naik ${ }^{1}$, V Ramakrishna Sajja ${ }^{2}$, P Jhansi Lakshmi ${ }^{3}$ and Venkatesulu $\mathrm{D}^{4}$ \\ 1, 2, 3, ${ }^{4}$ Department of Computer Science \& Engineering, Vignan's Foundation for \\ Science, Technology \& Research, India \\ 11dsbhupal@gmail.com, 22vramakrishnasajja@gmail.com, \\ 3laxmi.jhansi@gmail.com, ${ }^{4}$ drvenkatesulud43@gmail.com
}

\begin{abstract}
With the rapid development of the world population, large area of land is utilized to develop housing and the ability of producing food is reduced. Farming has become crucial in present trend and keeps food on the tables. Farming with IOT helps in mitigating the shortage of food by demanding the existing land for stronger utilization at minimum cost. Smart farming is a notion that quickly snaps on the agricultural field. This offers an automated farming techniques, useful data collection and high-rigor crop control. Sophisticated sensor based architecture is proposed to monitor the conditions of the farms by using sensors and the information extracted from these sensors is stored on the internet. This stored information is obtained and evaluated to forecast the condition of farms, according to a period of time. Based on this evaluation, the necessary improvements can be made with better farming conditions in future.
\end{abstract}

Keywords - IOT, Sensors, Smart farming, Agriculture, Food, Modem, Micro controller

\section{INTRODUCTION}

In India, farming is the only source that generates revenue for the agriculture community. Two-thirds of our population is based on farming for a livelihood. So for this reason, farming has become the back bone of Indian economy [1, 2]. Due to many problems, farmer suicides are leading into a large number across India because of the problems are faced as insufficient rainfall, irregular monsoons. These are not responsible and can be set directions to deliver by technology. At the right time, some of the problems can be solved by giving proper advices to the farmers. To harvest crops, some of the requirements like fertilizers, labors, pesticides, seeds and water are necessary. Based on the water availability, the main task of a farmer is to raise the capital. When they are unable to raise the capital in their own path, they depend on other sources like banks and some financial organizations. At this situation, the farmer depends on the crop for crediting the payments that are taken from banks and financial organizations. This may create very tough conditions if the crop fails. And sometimes, this may results pushing the farmer into some of the critical situations and causes relentless stress [3,5].

This type of crop failures can be avoided and some of the preventions are to be noticed with the available resources before dumping. There is only way to address these types of problems and increase the quality and quantity of crop production is by utilizing the IoT sensing technology. Farming with IOT helps in mitigating the shortage of food by demanding the existing land for stronger utilization at minimum cost. This technology

Received: May 23, 2019

Reviewed: August 21, 2019

Accepted: September 9, 2019

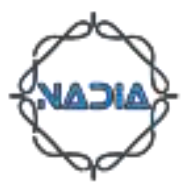


makes crops to be connected through the smart farming. IoT sensors in the farms are more capable of providing information to farmers about crops and used for monitoring the health of crops in earlier stages [6], [8].

Section - II describes the related work carried out by various researchers, detailed explanation of IOT \& Smart farming is given in Section-III and Section-IV, respectively, Section-V explains the drivers and barriers raised during their integration and our perception about solutions which is followed by Conclusion.

\section{RELATED WORK}

C. Perera, A. Zaslavsky, C. Liu, M. Compton, P. Christen and D. Georgakopoulos [7] led a study about enabling IOT and its applications in industries by a survey. The SOA models of IOT were introduced and discussed about their fundamental technologies. They also introduced some key applications by analyzing the challenges and future trends related to IOT. They mainly concentrated on the industrial applications and focused on the challenges and research opportunities which are possible for future researchers.

Nicoleta-Cristina Gaitan, Vasile Gheorghita Gaitan, Ioan Ungurean [4] surveyed on software architectures on IoT. From the proposed architectures the data are distributed by including a middleware layer in the internet. These architectures meet the requirements for IoT systems by including some existing technologies. M.U. Farooq, Muhammad Waseem, Sadia Mazhar, Anjum Khairi, Talha Kamal led study about emerging large scale of IoT technologies into networking used for monitoring the environment by embedding objects around us. They also discussed about IoT vision and highlighted various technologies and few issues related to those technologies.

N. Shashwathi, Priyam Borkotoky, Suhas K [16] proposed a set of farmer friendly technology services between the expertise of Agra-scientists and farmers. They also explain the benefits about taking the advice of agricultural experts for Chikku farm in Bangalore. This project has been spread across three years. In the first year, they have gathered the requirements and developed a model. In the second phase, some of the farmer friendly services are deployed on the IBM cloud platform using web and mobile clients.

Vidya Kumbhar [12] led a study on IT for Sustainable Agricultural Development in India. He developed this model to help farmers to increase their food productivity, which leads to their economic growth. The model was developed to track all types of information about farmers related to crops.

\section{INTERNET OF THINGS}

The term, IoT was introduced by the British pioneer Kevin Ashton in the year 1998 to describe a system with large number of objects or sensors that would be connected to the internet through communications to provide some services. In present days, IoT became more popular for characterizing the scenarios like connectivity and computing capability that extends to different objects and everyday items. The "thing" in IoT refers to any of the communicating or non-communicating object on earth $[9,10]$. This object represents both physical entities and digital entities by performing some computational tasks for people. IoT supports the interaction between "things" and allows more-complex structures by developing distributed applications and distributed computing. The working of IoT is done on the basis of Machine-to-Machine (M2M) communication and this M2M is defined for communicating between two machines without the involving manpower. Even non-connected entities in IOT can turn as IOT components [11, 13]. This technology sometimes understood as being identical with smart systems such as smart homes, smart enterprises, smart wearable, smart city and smart environment. The development of the current Internet yields information from the sensing environment and 
interacts with the physical world by utilizing existing Internet standards for providing services like communication, data transfer and applications.

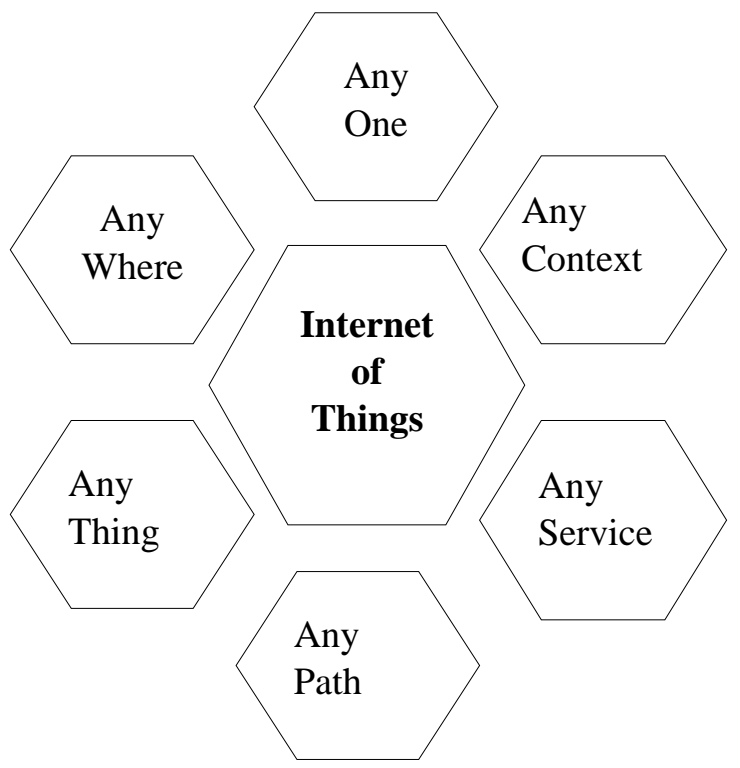

Fig. 1 Definition of IoT

\section{SMART FARMING}

The main goal of this Smart Farming is to optimize the harvesting land per unit by using modern methods to achieve best in terms of quality, quantity and financial return. The term smart farming is also known as Precision Farming which uses a wide range of technologies, including GPS services, sensors and etc. These technologies are very much required in agriculture sector includes with climate forecasting, robotics, science based solutions, environmental controls and etc. An M2M system is necessary to analyze the data and initiates the responses to the information received $[14,15]$. In this perspective of the Machine-to-Machine communication system, this technology around it vision enables some key transformations of the agriculture towards the vision of smart farming. The impact of this technology in farming delivers the connectivity between the sensors and communication systems and these sensors spreads in different areas like food traceability, land management and environmental monitoring $[17,18]$. The intricacy of smart farming can reflect the agricultural ecosystem in the following ways.

Wireless Services: The wireless services include a collection of wireless sensor devices used to monitor the physical and environmental conditions [19].

Machines and Equipments: The machines are the elements used to direct the work in agriculture in improving the production and farming techniques. The most widely used machinery in agriculture work fields are Tractors, combines and etc. The equipments in the field of agriculture are designed to open furrows in the earth [20, 21]. The various types of equipments are ploughs, fence, blade, handlebar and etc. 


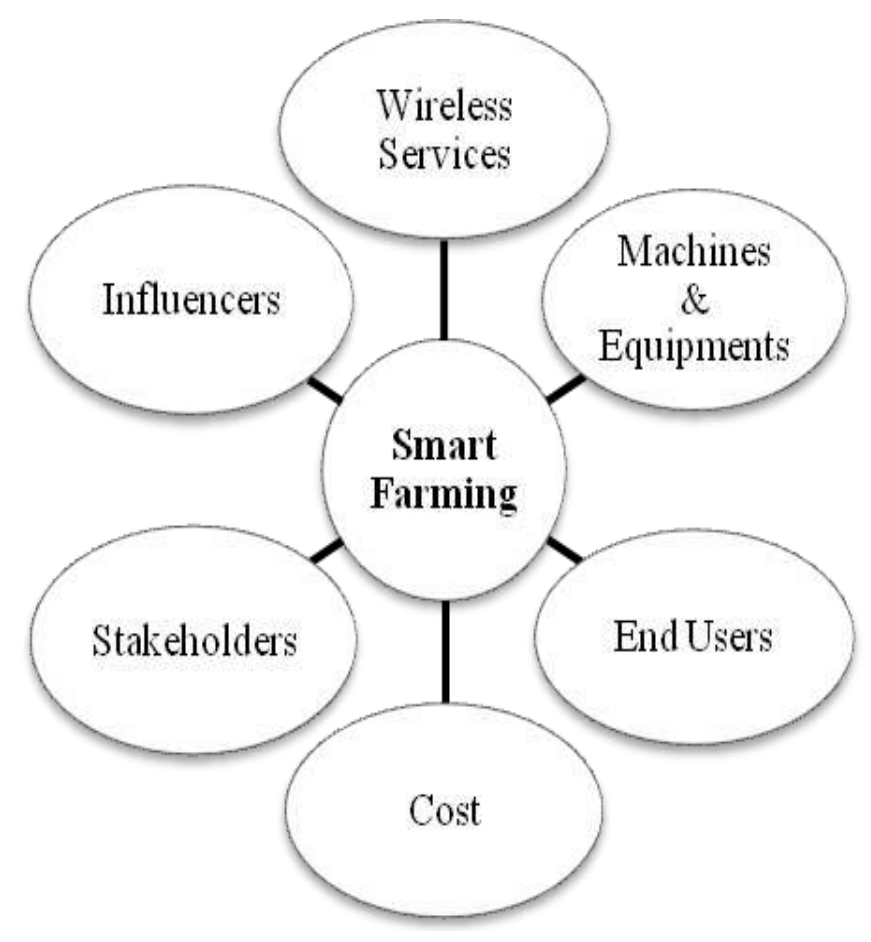

Fig. 2 Architecture for Smart Farming Ecosystem

End Users: The end users in smart farming are the growers and managers at the back office systems. They are also considered as a farmer's co-operatives which can help smaller farmers with advice and funding.

Cost: In spite of larger farms, the cost would be a major problem. The factors like soilmapping, fertilizer applications, machinery, weather data generates vast quantities of information. This information is collected by farm offices by these factors are in the field of farming.

Stakeholders: Stakeholders role in agriculture is broad. The range of these stakeholders starts from large business fields like finance, engineering, retailers to industry are well expertise in farming with the contribution of small suppliers.

Influencers: Influencers plays an important role in word-of-mouth marketing in the field of agriculture. The benefits of influence marketing are numerous. Partnering with an influencer can be a cost effective form of high-quality content with built in distribution.

The working of smart devices in farming allows farmers to apply amount of resources like water, fertilizers, etc... at the right time and right place in right time. This type of farming is a priceless tool for composing chemicals in soil. This system operates many machines and equipments very smartly and collects the data based on these equipments from the field by configuring the problems when they are detected. The devices in this field will be user friendly and helps the farmers to plan irrigation and more activities based on environmental and soil conditions. The parameters like temperature, humidity, $\mathrm{pH}$ value and soil moisture can be monitored by these device controllers and can be informed through some graphical representations. The devices can be configured by farmers for receiving important alerts from the field parameters in the form of SMS messages in his mobile through programming. In this way, most of the situations can be monitored and controlled in agriculture field by using some remotely operated devices. 
The Smart devices in the agriculture field consist of some key features. They are as follows:

- Different agricultural parameters like Temperature, Wind, Humidity, and Moisture can be controlled and monitored by using sensors.

- Generates and Schedules a plan for irrigation and fertilization.

- Data can be obtained through wireless speckles.

- Provides external memory interface for the purpose of feeding and desertification.

- Provides awareness to the farmers by alerting while he is away from the field.

- Controls the equipments in the field through sensor devices like mobile phones, Tablets, computers etc.

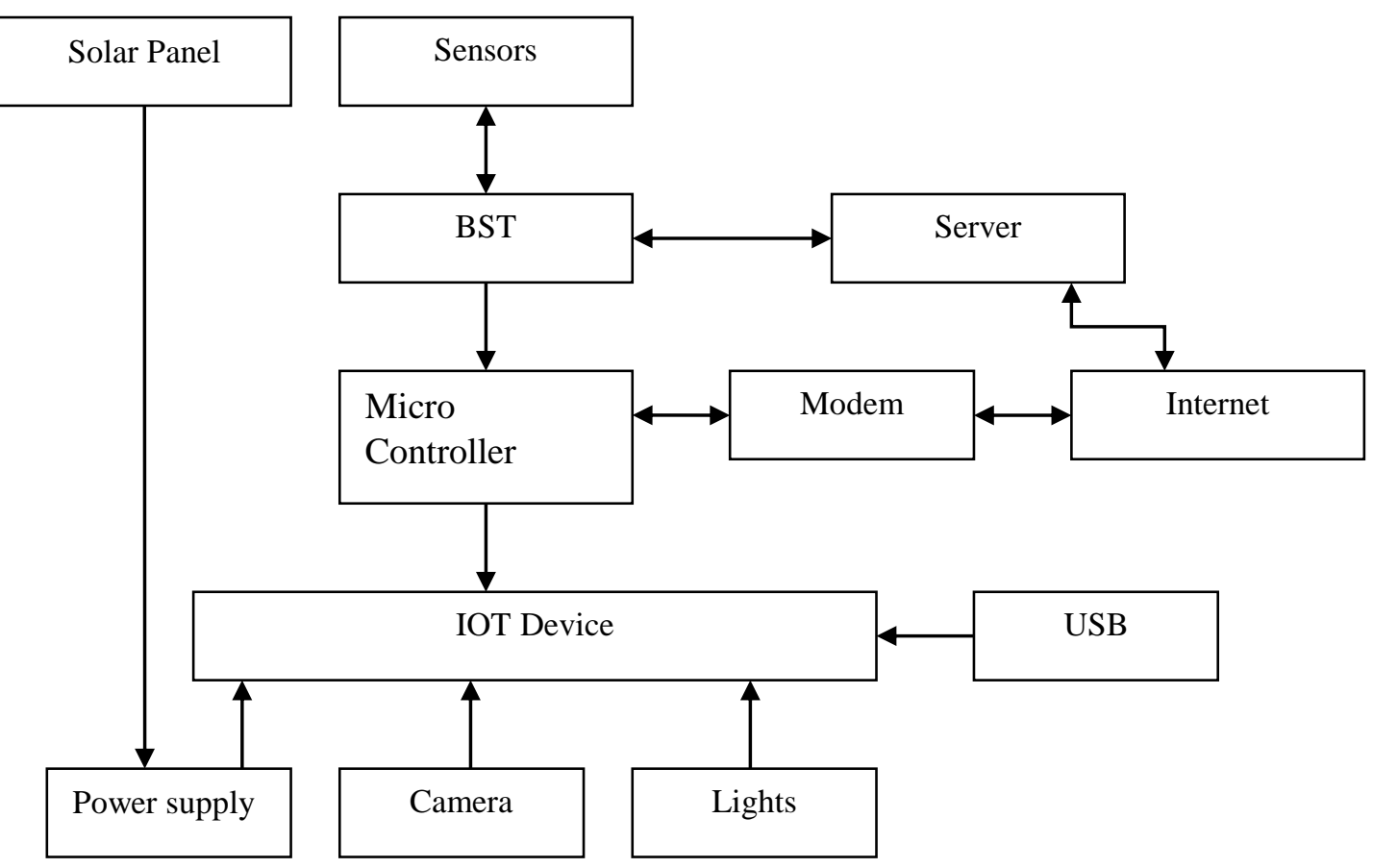

Fig. 3 Architecture of Smart Farming System

The above figure represents the architecture of the smart farming system in the agriculture. The block diagram consists of following:

1. Solar Panel acts as a power source and offers an opportunity to stabilize the energy cost to the farmers. These solar panels are of three types namely:

a. Grid solar: This reduces the final cost for the power utilization for the home and business. The energy generated from the sun is utilized by this panel and earns the credits which are used further.

b. Hybrid solar: These are used as power bank to the systems which are used for backup purpose. The power is supplied to the grid via battery bank in the event of power of outage.

c. Off-grid solar: These type of solar panels are independently used for a remote location and are limited. 
2. Sensors: The sensors form a network with each other. A master sensor can act as a gateway by collecting the sensor readings to the internet using mobile connectivity. This installation requires any of the SIM cards to connect to the internet. Node sensor is also having similar functionality as master sensor [22], [23]. Node sensor can also acts as a gateway by conducting the data to the internet where as master sensor pushes data directly to the internet. Most often, spectral sensors are used to examine the growth of plants in soils with different levels of nutrients.

3. Base Station: In the agriculture field, Base station acts as a piece of equipment with wireless communication between user and a network.

4. Microcontroller: The Microcontroller plays a major role in field of agriculture by transferring the information about the motors in the farm. When the motor is turned $\mathrm{ON}$ by the controller then the pumping functionality of the water from the ground is activated. In the other case, it constantly monitors the dizitized parameters of the various sensors and verifies those parameters with some predefined threshold values.

5. Server: This can act as a centralized system to store and share data among farmer and internet.

6. Modem: This can be used as a wireless device for connectivity to transfer the data between source to destination. The source and destination in the farm may be office and farmer, vehicle and vehicle and etc.

7. Internet: This is a global computer network that provides a variety of information and communication facilities.

8. IOT Device: This may be any of the smart devices.

9. USB: It can be a flash drive that can act as portable storage device.

10. Power: It is one of the major source of energy used for irrigation and controlling the motors and lights in the farming.

11. Camera: The role of camera in the field of agriculture plays a vital role. The key uses of these cameras are:

- Identification of the intruders

- Protect the water supplies

- Prevent break-ins

- Vehicle Tracking

- Employee monitoring

12. Lights: A popular light source with eco-friendly features is LED. This LED is good for growth of plants by improving the life time and can have huge business opportunities by maintaining the quality. To maintain the proper growth of plants in the farms, LED screens are to be installed to provide the enough light for germination. 
The applications in the area of smart farming are complicated. The structure of this smart farming is described in the following figure.

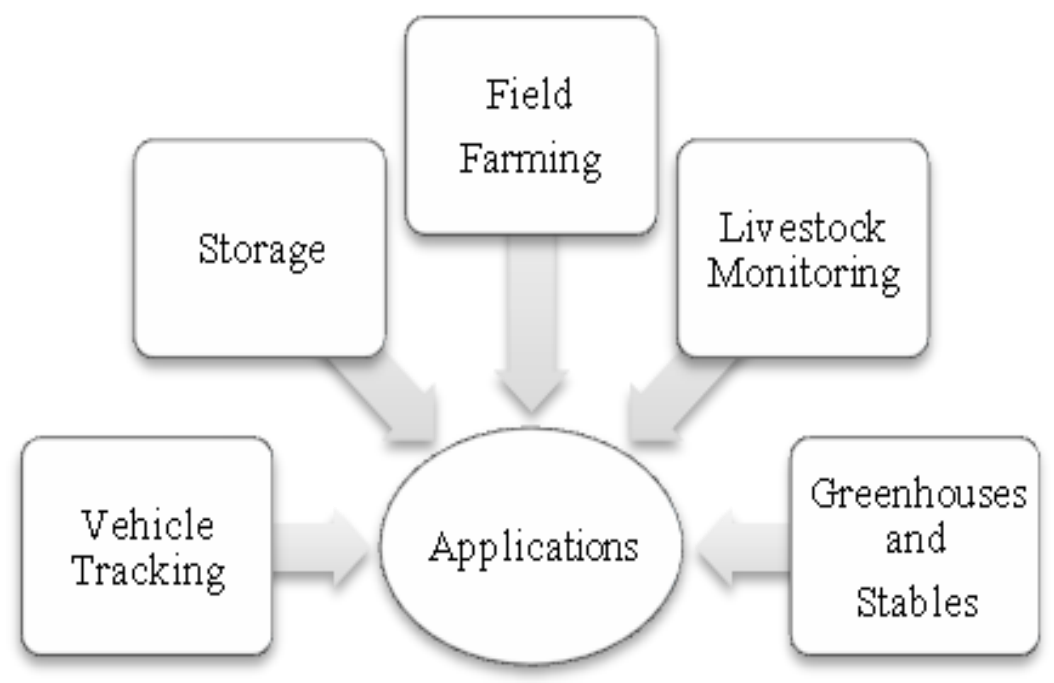

Fig. 4 Applications from Smart Farming

The following steps describe the Drivers and Barriers in the adoption of Smart Farming into agriculture.

The Drivers are:

- To increase efficiency there should be a need to reduce waste.

- The immediate response is needed when there is a change in climate.

- Assistance is needed in a farming area from public and projects.

- Soil erosion is to be addressed before thorough farming.

- Many industries use an M2M based system for monitoring and Tracking purposes.

- Cost of smart devices like sensors and their connectivity must be reduced.

The Barriers are:

- Investments on device installations in a farm cannot be returned once they have been directed.

- Many issues like weather and political may create several problems by inheriting in the industry.

- Based on data collected from the owner, many queries cannot be resolved.

- Lack of Wireless and broadband facilities in Rural areas.

- No standard development in sensor networks.

- No maturity in Specialist agricultural software's.

\section{CONCLUSION}

In this paper, we discussed about farming with IoT for providing many useful services to the farmers in society in future. Many of the smart applications can be developed by the IOT and vastly utilized by users. The working of smart devices in farming allows farmers to apply amount of many resources at right time and right place in right time. This type of farming is having less cost. This system operates many machines and equipments very smartly and collects the data based on these equipments from the field by configuring the problems when they are detected. Farming with IOT helps in mitigating the shortage of food by demanding the existing land for stronger utilization at 
minimum cost. Smart farming is a notion that quickly snaps on the agricultural field. This offers automated farming techniques, useful data collection and high-rigor crop control. The main goal of this Smart Farming is to optimize the harvesting land per unit by using modern methods to achieve best in terms of quality, quantity and financial return. Finally, some of the probable solutions are examined by approaching some related research initiatives.

\section{REFERENCES}

[1] S. K. Dash, S. Mohapatra, and P. K. Pattnaik."A Survey of Application of Wireless Sensor Network Using Cloud Computing" International Journal of Computer Science \& Engineering Technologies (EISSN: 2044-6004), 1(4):50-55, 2010.

[2] Dave Evans, "The Internet of Things How the Next Evolution of the Internet Is Changing Everything", Whitepaper, Cisco Internet Business Solutions Group (IBSG), April 2011.

[3] Gerd Kortuem, Fahim Kawsar, Daniel Fitton, and Vasughi Sundramoorthi, "Smart Objects and Building Blocks of Internet of Things", IEEE Internet Computing Journal, volume 14, issue 1, Jan.-February, 2010.

[4] Nicoleta-Cristina Gaitan, Vasile Gheorghita Gaitan, Ioan Ungurean" A Survey on the Internet of Things Software Arhitecture" ) International Journal of Advanced Computer Science and Applications, Vol. 6, No. 12, 2015.

[5] S. B. Shen, Q. L. Fan, P. Zong, Q. Y. Mao and W. Huang. Study on the Architecture and Associated Technologies for Internet of Things. Journal of Nanjing University of Posts and Telecommunications (Natural Science), 2009, 29(6): 1-11.

[6] Rafiullah Khan, Sarmad Ullah Khan, Rifaqat Zaheer, and Shahid Khan, "Future Internet: The Internet of Things Architecture,Possible Applications and Key Challenges", in the proceedings of $10^{\text {th }}$ International Conference on Frontiers of Information Technology, Islamabad, Pakistan, 17-19 December, 2012.

[7] C. Perera, A. Zaslavsky, C. Liu, M. Compton, P. Christen and D. Georgakopoulos, "Sensor search techniques for sensing as a service architecture for the internet of things", Sensors Journal, IEEE, vol. 14, no. 2, pp. 406-420, 2014.

[8] M. Eisenhauer, P. Rosengren, and P. Antolin, "A development platform for integrating wireless devices and sensors into ambient intelligence systems," in Sensor, Mesh and Ad Hoc Communications and Networks Workshops, 2009. SECON Workshops' 09. 6th Annual IEEE Communications Society Conference on. IEEE, 2009.

[9] Thirunavukarasu B, Dr T.Kalaikumaran, Dr S.Karthik, "Integration Of Data Mining And Internet Of Things -Improved Athlete Performance And Health Care System" International Journal of Technical Research and Applications, November-December, 2014.

[10] Barreiro P., Correa E. C., Arranz F. J., Diezma B., Ruiz L., Villarroel M., Robla J. I. and Garcia-Hierro F. J., Smart Sensing Applications in Agriculture and Food Industry, 2011.

[11] Jadhav and Shinde, "Web Based Information System for Agriculture", In International Journal of Innovative Technology and creative engineering, Vol 1, No.2, February, 2011.

[12] Vidya Kumbhar, "IT for sustainable agriculture development in India", In the proc. of the 3rd National Conf. India-Com, February 26-27, 2009.

[13] Robert Jensen, "Information, Efficiency and Welfare in Agricultural Markets", In the proceedings of the 27thInternational Association of Agricultural Economists Conference, Beijing, China, 2009.

[14] Subba Rao,“ Indian Agriculture-Past Laurels \& Future Challenges”, In Indian Agriculture: Current Status, Prospects \& Challenges, 27th Convention of Indian Agricultural. University Association. 9-11 December,2002.

[15] S. Poslad, Ubiquitous Computing: Smart Devices, Environments and Interactions, John Wiley \& Sons, Ltd., p. 75, 2009.

[16] N. Shashwathi, Priyam Borkotoky, Suhas K, “ Smart Farming: A Step towards Techno-Savvy Agriculture" International Journal of Computer Applications (0975 - 8887) Volume 57- No.18, November 2012.

[17] Varaprasad Janamala, "Parameterization of Stand-Alone Solar PV System Performance - An IoT Solution", International Journal of Advanced Science and Technology, SERSC Australia, ISSN: 20054238 (Print); 2207-6360 (Online), vol. 106, pp. 1-8, September, 2017.

[18] Ho-Kyung Yang, Hyun-Jong Cha and You-Jin Song, "A Study of Secure Distributed Management of Sensing Data in IoT Environment", International Journal of Advanced Science and Technology, NADIA, ISSN: 2005-4238 (Print); 2207-6360 (Online), vol. 124, pp. 21-32, March, 2019.

[19] Sang-Hee Kweon, Se-Jin Kim, Myung-Bean Song and Ya-Ru Bao, "A Semantic Network Analysis of 4th Industry Revolution: News Frame for on Drone, AI, Big Data and IoT News", International Journal of Advanced Science and Technology, SERSC Australia, ISSN: 2005-4238 (Print); 2207-6360 (Online), vol. 111, pp. 115-1281, February, 2018. 
[20] Alpesh Mehta and Nirvesh Mehta, "Algae Farming: A Way Towards Prosperity", International Journal of Advanced Science and Technology, SERSC Australia, ISSN: 2005-4238 (Print); 2207-6360 (Online), vol. 81, pp. 53-62, August, 2015.

[21] Dr. C. Mariotti, "Plate Element Formulation for a Discrete Element Method", International Journal of Advanced Science and Technology, SERSC Australia, ISSN: 2005-4238 (Print); 2207-6360 (Online), vol. 94, pp. 13-22, September, 2016.

[22] Jin-young Song and Dea-woo Park, "Preemptive Cyber Response Strategy and IoT Forensic Evidence", International Journal of Advanced Science and Technology, SERSC Australia, ISSN: 2005-4238 (Print); 2207-6360 (Online), vol. 117, pp. 129-138, August, 2018.

[23] Siwoo Byun, "Viability-Based Replication Management Scheme for Reliable IoT Data Services", International Journal of Advanced Science and Technology, NADIA, ISSN: 2005-4238 (Print); 22076360 (Online), vol. 124, pp. 89-102, March, 2019. 
International Journal of Control and Automation Vol. 12, No. 9 (2019) 